\title{
Laparoscopic Cholecystectomy: Unusual Septic Complications Because of Gallstone Spillage
}

The natural history of spilled stones in the peritoneal cavity at the time of laparoscopic cholecystectomy is not well known. We describe two patients who experienced septic complications several months after laparoscopic cholecystectomy with stone spillage.

\section{Case 1}

A 61-year-old woman returned to hospital one month after laparoscopic cholecystectomy with a right lung abscess, which regressed with antibiotic treatment. Seven months later the abscess relapsed but dit not respond to antibiotic treatment and percutaneous drainage (Figure 1) and the patient underwent surgery. At thoracotomy an abscess containing several pigment stones and a sealed off peritoneopleural fistula were found. The abscess area was debrided and drained. The patient is now well, with no further complaints.

\section{Case 2}

A 64-year-old man came to hospital six months after laparoscopic cholecystectomy with a painful swelling in the back. An ultrasound scan showed an abscess with gallstones within (Figure 2). This was drained and multiple small bilirubinate stones were found and extracted. One month later he returned to hospital with a right pleural effusion. Thoracentesis revealed a $300-\mathrm{ml}$ exudate. After two years the patient is asymptomatic. A CT scan showed residual fibrotic changes at the right pleural base and a small perihepatic fluid collection in which two gallstones remain.

Laparoscopic cholecystectomy has become the procedure of choice for symptomatic cholelithiasis [1]. Initially it was believed that gallstone spillage was a benign event [2], but as experience with the procedure increases more complications are encountered. Intra-abdominal, subphrenic and subcutaneous abscesses have been reported, and cutaneous fistulae and small bowel obstruction secondary to gallstone abscess $[3,4]$. In our patients the stones might have spilled into the subphrenic space during gallbladder placement above the liver. Alternatively, they could have fallen into the subhepatic space and migrated up to the subphrenic space. In case 1, a stone eroded through the diaphragm up to the pleural space, where it formed an abscess. In case 2 , stones migrated to the back and some remained localized to the superior face of the liver.

The complication rate from retained stones is not high enough to warrant immediate conversion (5), but they can be a source of infectious complications, and every effort should be made to remove all of them.

N. Carvalho, R. Lebre, D. Canário, J. Giria Dept. of Surgery, Hospital Garcia de Orta, Almada, Portugal

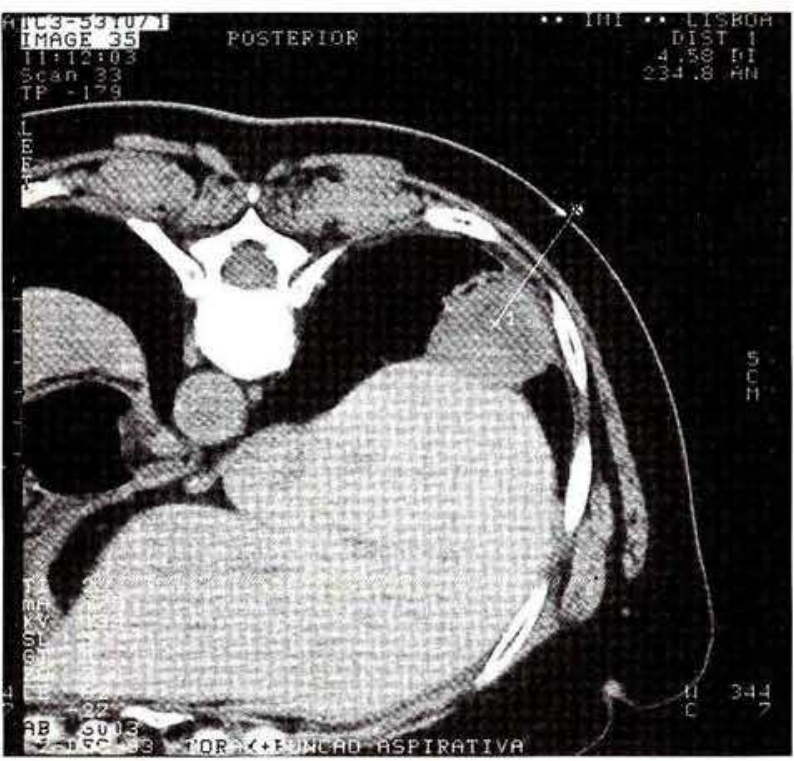

Figure 1 Computed tomography (CT) scan of patient with right lung abscess (case 1) before abscess drainage 


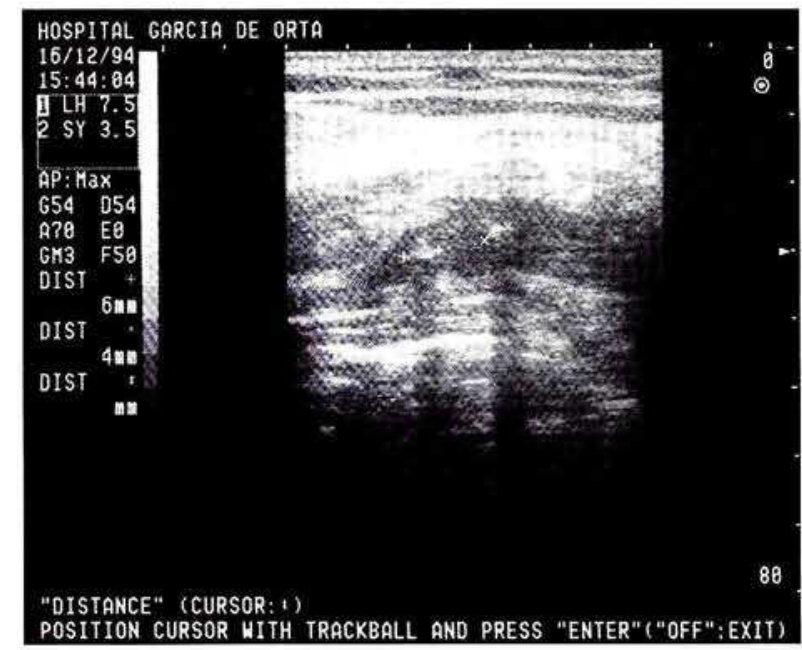

\section{References}

1. Johnston S, O'Malley K, McEntee G, et al. The need to retrieve the dropped stone during laparoscopic cholecystectomy. Am J Surg 1994; 167: 608-10

Figure 2 Ultrasonogram of patient's back (case 2), showing a fluid collection with two echogenic densities and their respective acoustic shadows

2. Leslie KA, Rankin RN, Duff JH. Lost gallstones during laparoscopic cholecystectomy: are they really benign? Can J Surg 1994; 37: 240-2
3. Eisenstal S. Abdominal wall abscess due to spilled gallstones. Surg Laparosc Endosc 1993; 3: 485-6

4. Birkett DH. Spilled cells, spilled clips, spilled stones [editorial]. Surg Endosc 1995; 9: 269-71

5. Cullis SNR, Jeffery PC, McLauchan $\mathrm{G}$, Bornman PC. Intraperitoneal abscess after laparoscopic cholecystectomy. Surg Laparosc Endosc 1992; 2: $337-8$

Corresponding Author

N. Carvalho, M.D.

Dept. of Surgery

Hospital Garcia de Orta

2800 Almada

Portugal

Fax: $\quad+351$ (1) 2957004

E-mail: rlebre@mail.telepac.pt 